\title{
Interprofessional oral health initiative in a nondental, American Indian setting
}

\section{Authors: Kate L. Murphy \& Laura S. Larsson}

This is the peer reviewed version of the following article: see full citation below, which has been published in final form at https://dx.doi.org/10.1002/2327-6924.12517. This article may be used for non-commercial purposes in accordance with Wiley Terms and Conditions for Self-Archiving.

Murphy, Kate L. , and Laura S. Larsson. "Interprofessional oral health initiative in a nondental, American Indian setting." Journal of the American Association of Nurse Practitioners 29, no. 12 (September 2017):733-740 . DOI: 10.1002/2327-6924.12517.

Made available through Montana State University's $\underline{\text { ScholarWorks }}$ scholarworks. montana.edu 


\title{
Interprofessional oral health initiative in a nondental, American Indian setting
}

Kate L. Murphy, BSN, RN, DNP, FNP-BC (Nurse Practitioner) \& Laura S. Larsson, (D) PhD, MPH, RN (Associate Professor)

College of Nursing, Montana State University, Bozeman, Montana

\begin{abstract}
Background and purpose: Tooth decay is the most common chronic childhood disease and American Indian (AI) children are at increased risk. Pediatric primary care providers are in an opportune position to reduce tooth decay. The purpose of this study was to integrate and evaluate a pediatric oral health project in an AI, pediatric primary care setting.

Methods: The intervention set included caregiver education, caries risk assessment, and a same-day dental home referral. All caregiver/child dyads age birth to 5 years presenting to the pediatric clinic were eligible $(n=47)$.

Conclusions: Most children $(n=35,91.1 \%)$ were scored as high risk for caries development. Of those with first tooth eruption $(n=36)$, ten had healthy teeth $(27.8 \%)$ and seven had seen a dentist in the past 3 months $(19.4 \%)$. All others were referred to a dentist $(n=29)$ and 21 families $(72.4 \%)$ completed the referral.

Implications for practice: In fewer than 5 min per appointment $(x=$ $4.73 \mathrm{~min})$, the primary care provider integrated oral health screening, education, and referral into the well-child visit. Oral health is part of total health, and thus should be incorporated into routine well-child visits.
\end{abstract}

\section{Introduction}

Tooth decay, also known as early childhood caries (ECC), is a public health crisis. The most common chronic childhood disease, the prevalence of ECC in U.S. children aged $2-5$ is $23 \%$ and increases to $55.7 \%$ for children aged 6-8 (Dye, Thornton-Evans, Li, \& Iafolla, 2015 ). A multifactorial infectious disease that can precipitate as soon as the first tooth begins to erupt, ECC can progress rapidly, causing detrimental effects on a child's overall health.

Caries rates among American Indian (AI) children aged 2-4 are five times that of non-AI children, and the rate of untreated primary tooth decay is nearly three times greater than in the general population (Schroth, Harrison, \& Moffatt, 2009; U.S. Public Health Service, 2000). ECC prevalence in AI 1-year-olds was $21.2 \%$ and $43.7 \%$ in 2 -year-olds (Ricks, Phipps, \& Bruerd, 2015). The prevalence of ECC is especially high among AI children for reasons that span the ecologic framework including poverty, diet, limited access to prevention and treatment services (American Academy of Pediatrics, 2011; Warren et al., 2009), and poor oral health literacy among caregivers (Lee et al., 2011; Vann, Lee, Baker, \& Divaris, 2010).
Untreated cavities can lead to a multitude of complications, including pain, infection, difficulty with eating and speaking, and delayed speech (American Academy of Pediatrics, 2011). Children experiencing ECC have a much greater probability of subsequent caries in both primary and permanent dentition (Du et al., 2017; Kawashita, Kitamura, \& Saito, 2011). Despite being preventable, in the absence of proper care ECC often progresses until the tooth is destroyed (Kawashita et al., 2011). Chronic ECC can result in systemic health issues and has been associated with respiratory tract infections and acute otitis media (American Academy of Pediatrics, 2011). A more severe consequence of ECC is extensive treatment and surgical intervention that requires general anesthesia (American Academy of Pediatrics, 2011). Yu, Martin, Terpak, and Curtis (2009) reported that ECC was the second most frequent diagnosis requiring surgery (12\%) among 83,973 children younger than 6 years of age.

One of the principal barriers to proper oral health care for families is limited access. Almost all infants and 1year-olds had office-based physician visits annually (89\%), compared with dental visits $(1.5 \%)$. Visits to physicians 
outnumbered visits to dentists 250:1 for this age group (American Academy of Pediatrics, 2008, p. 1387). Therefore, adequately addressing ECC requires interprofessional collaboration. Pediatric primary care providers are in an opportune position to provide oral health screenings, education, interventions, and dental referrals (Kagihara, Niederhauser, \& Stark, 2009; Kawashita et al., 2011).

Based on a thorough review of literature, a three-part oral health intervention was designed and implemented in an AI, pediatric, primary-care setting. The goal was to facilitate the integration of sustainable pediatric oral health initiatives into the well-child appointment. Three specific aims included (a) educate $100 \%$ of parents/caregivers of children age birth to 5 years on pediatric oral health promotion, ECC prevention, and self-care behaviors; (b) increase dental home referrals of eligible children by $100 \%$ in AI children younger than 5 years with first tooth eruption; and (c) conduct a caries risk assessment on $100 \%$ of the AI pediatric patients age 6-months to 5 years, or younger with first tooth eruption.

With more children receiving services in primary care settings than dental settings, pediatricians and other pediatric healthcare providers may be the only sources of preventative oral health education and care for very young children (Lewis et al., 2009). To prevent ECC, reduce costs, and increase utilization of subsequent preventive services (Nowak, Casamassimo, Scott, \& Moulton, 2014; Savage, 2004), the primary care providers' role in pediatric oral health should include routine assessment of pediatric oral health status at well-child visits, verification of an established dental home by the first year of life (American Academy of Pediatric Dentistry, 2015; Ramos-Gomez, Crystal, Ng, Crall, \& Featherstone, 2010; Ramos-Gomez, Crystal, Ng, Tinanoff, \& Featherstone, 2010), provision of education and anticipatory guidance for the primary caregiver, caries risk assessment (Duderstadt, 2014), and routine fluoride varnish (FV) application at 6-month intervals (American Academy of Pediatric Dentistry, 2014).

At this time, many state Medicaid programs will reimburse nondental professionals for oral health prevention services, but require that they receive oral health education to qualify (Sams, Rozier, Wilder, \& Quinonez, 2013). Researchers evaluated the impact of Colorado's nondental provider oral health education program. From 2009 to 2012, the proportion of low-income children who received oral health preventative services from a medical professional increased 16-fold (Braun et al., 2015). Pierce, Rozier, and Vann (2002) found that dental screenings were easily incorporated into a busy pediatrics practice, and that doing so resulted in the identification and referral of those children who needed to be seen by a dentist.

Oral health literacy was emphasized in this project because pediatric clients depend on their caregiver (e.g., par- ent, grandparent, legal guardian) for access to oral health care (Vann et al., 2010). In "Oral Health in America," the Surgeon General stressed that if parents are unfamiliar with the importance and care of their child's primary teeth, they are unlikely to take appropriate action to prevent ECC or may fail to seek professional services (U.S. Public Health Service, 2000).

Bridges et al. (2014) found caregivers' education attainment, income, and age were all negatively associated with decayed, missing, filled surfaces (dmfs) scores, suggesting that younger parents with fewer years of education and less income were more likely to have children with tooth decay than their counterparts. Miller, Lee, DeWalt, and Vann (2010) concluded that caregiver literacy scores, measured using the Rapid Estimate of Adult Literacy in Dentistry (REALD-30) were positively linked to the clinical oral health status of their children $(\mathrm{OR}=1.14,95 \%$ CI $[1.05,1.25], P=0.003)$. Lee, Divaris, Baker, Rozier, Lee, and Vann (2011) studied racial differences of oral health literacy and determined that Caucasians had overall higher oral health literacy, with a mean score of 17.4 $(\mathrm{SE}=0.2)$, compared to a mean score of $13.7(\mathrm{SE}=0.3)$ for AIs and 15.3 (SE = 0.2) for African Americans. Thus, it was demonstrated that children from minority populations, even after controlling for important sociodemographic characteristics, were at an even greater risk for dental decay because of poor caregiver oral health literacy.

An oral health education intervention was applied with first-time mothers during pregnancy and again when the infant was 6 and 12 months old. The oral health status of the child was then assessed at age 20 months. The authors found that the intervention reduced the frequency of ECC from $8.1 \%$ to $1.1 \%$ (relative risk $=0.14$ ) in two-parent families and from $16.3 \%$ to $4.5 \%$ (relative risk $=0.28$ ) in one-parent families. This study demonstrated that increasing parental oral health literacy decreased the child's risk for ECC development (Plutzer \& Keirse, 2011).

In summary, an oral health screening, risk assessment, anticipatory guidance, and referral to a dental home by age 1 are critical elements to preventing ECC. These early prevention strategies are less invasive and more cost-effective than reactive interventions.

\section{Methods}

\section{Design}

This nonexperimental quality improvement project was designed to improve the oral health status of a convenience sample of AI pediatric clients through a threepart intervention; a caries risk assessment, oral health education, and a dental referral. This project promoted early education and intervention to reduce ECC. It was the purpose of this project to demonstrate the successful 
integration of well-child and well-dental visits into a combined same day event. Under the request of the local dental clinic, children who did not have visible tooth eruption yet and those who had seen a dental provider less than 3 months prior were not sent for dental referral.

\section{Sample and setting}

The setting for this project was an Indian Health Service pediatric clinic in a small hospital located in the plains of the northwestern United States. The dental clinic was across the hall from the pediatric clinic. The pediatric clinic was routinely staffed with one pediatric nurse practitioner, serving as the sole primary care provider, one nurse, one nurse's assistant, and two receptionists. The full service dental clinic was routinely staffed with three general fulltime dentists, one endodontist, one contract general dentist, one pediatric part-time dentist, one part-time oral surgeon, one dental hygienist, one receptionist, and eight dental assistants. Indian Health Services in conjunction with Medicaid provides the main source of pediatric health services reimbursement.

This AI reservation community is a sovereign territory with a population of approximately 11,000 people. The community water supply is not fluoridated.

\section{Theoretical framework}

Pender's (1982) Health Promotion Model (HPM) was used in this project to better understand both the problems and potential solutions to poor pediatric oral health. ECC was understood as a disease with contributing factors across the social ecologic framework. More than exploring individual level attributes, the HPM combined social, family, policy, and structural dimensions into understanding the problem of ECC in the project setting.

The HPM explains that individuals interact with their environment, each serving to transform the other. Nurse practitioners are part of this environment and can exert a positive or negative effect on the adoption of health promoting behavior by children and their caregivers. The endpoint of the HPM is improving health promoting behavior through nursing action. These constructs were operationalized in this project to reduce ECC by improving pediatric oral health care through interdisciplinary assessment and collaboration.

\section{Sample characteristics}

All children birth to 5 years presenting to the AI pediatric clinic for a routine well-child visit $(n=47)$ during a 2 week period were eligible and invited to participate. All 47 dyads with ages ranging from 1 week to 67 months $(M=$ 27.81 months, $S D=20.62$ ) consented to participation. To

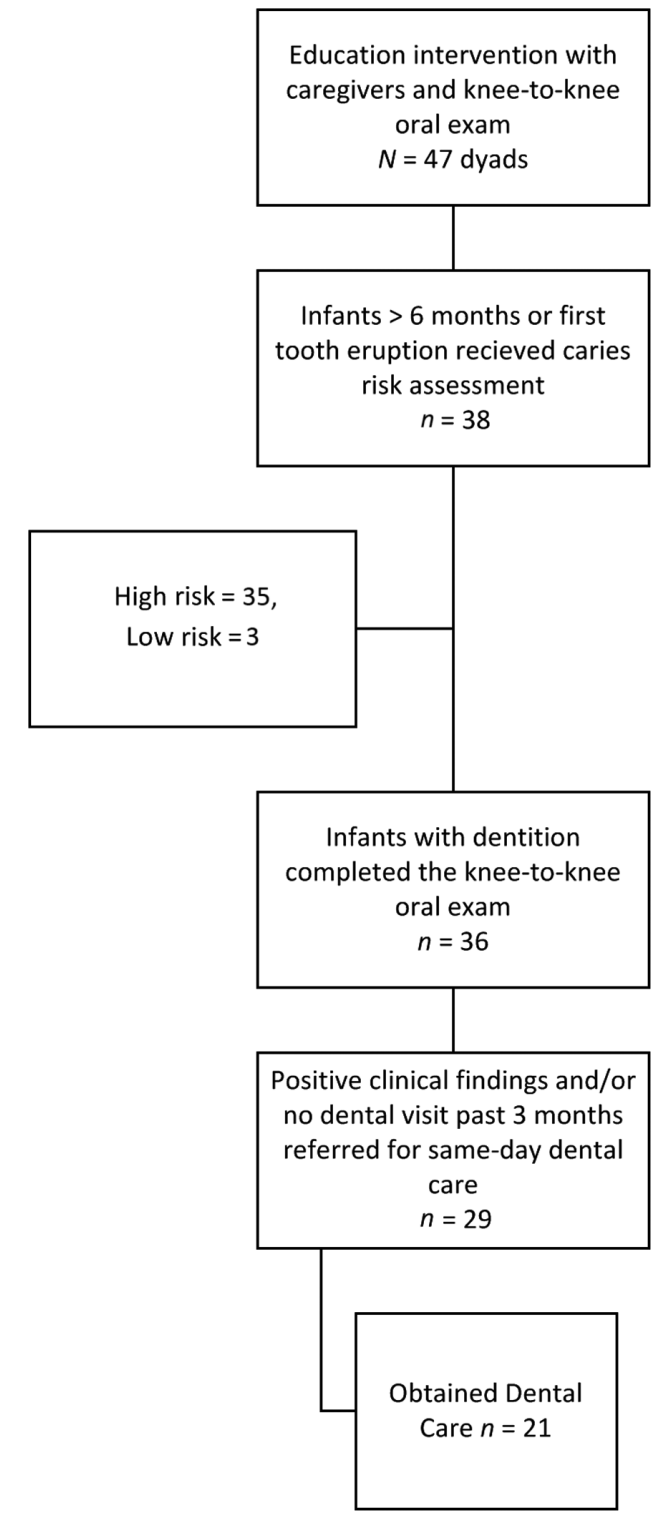

Figure 1 Diagram depicting participant flow through assessment, allocation, follow-up, and analysis. Children aged $0-5$ and their caregivers $(n=47)$ participated in this project designed to improve oral health access and track completed referrals for prevention of early childhood caries. The caries risk assessment was completed with all infants older than 6 months. The oral examination was initiated with all participants but clinical findings were only assessed if the infant had any teeth erupted.

be eligible for the caries risk assessment, the child had to be at least 6 months old or have had their first tooth erupt (see Figure 1).

\section{Data collection}

Montana State University Institutional Review Board approval (\#KT050615) and Tribal Institutional Review 
Board approval (\#15-01) were granted prior to project implementation. Caregivers provided written informed consent prior to participation, and were provided with a signed copy of the document. The primary care provider explained to subjects and caregivers their right to withdraw at any time and that their decisions to participate would not impact the care they received. Caregivers accompanied their child throughout the intervention. No financial incentives were offered.

\section{Instrumentation}

Data collection tools included a customized data collection sheet, dental referral tracking slip, and the Oral Health Risk Assessment Tool (OHRAT) for the caries risk assessment (Boulter, Crystal, Duncan, Keels, \& Ramos-Gomez, 2011). Clinicians who pilot-tested the OHRAT administered the assessment in just 2 min during the well-child visit. Additionally, they increased identification and referral of high-risk patients from $11 \%$ to $87.5 \%$ (Boulter et al., 2011 ). The 17 yes/no items consist of six risk and four protective items for caries and seven items related to clinical findings. Each child is then designated by the primary care provider as low or high risk for caries development (see Table 1). Items are not scored but instead provide opportunities to discuss each factor with the caregiver and inform the judgment of the primary care provider whether or not to refer the child for a dental appointment. It is important to note that the OHRAT was adapted specifically for use by nondental providers (Boulter et al., 2011), reflects the best available evidence for caries risk assessment (Twetman, 2016; Twetman, Fontana, \& Featherstone, 2013), and is endorsed by the American Academy of Pediatrics and the National Interprofessional Initiative on Oral Health.

The primary care provider completed the Smiles for Life Curriculum (Clark et al., 2010) and successfully completed supervised oral health assessments before beginning this project. The supervising dentist confirmed her clinical findings and endorsed her referral decisions in all cases.

\section{Procedure}

After completing the informed consent process, the primary care provider completed the caries risk assessment for participants 6 months old or with first tooth eruption. Next, the primary care provider conducted a knee-to-knee oral health screening (Clark et al., 2010; Ramos-Gomez et al., 2010) on all children, even those without teeth, to familiarize the child and the caregiver with the process. The primary care provider documented clinical findings for those with teeth. During these procedures, the primary care provider provided age-appropriate guidance on promoting healthy oral health behaviors such as caries
Table 1 Pediatric oral health outreach and caries risk assessment results summary

\begin{tabular}{|c|c|c|}
\hline Characteristic & $n$ & Percentage \\
\hline Received education & 47 & 100 \\
\hline Would accept FV in clinic & 47 & 100 \\
\hline Knee-to-knee oral cavity inspection & 47 & 100 \\
\hline Eligible for caries risk assessment ${ }^{a}$ & 38 & 80.85 \\
\hline \multicolumn{3}{|l|}{ Caries risk category } \\
\hline High & 35 & 91.10 \\
\hline Low & 3 & 7.89 \\
\hline \multicolumn{3}{|l|}{ Protective factors } \\
\hline Existing dental home & 19 & 52.78 \\
\hline Dental visit past 3 months & 7 & 19.44 \\
\hline Fluoridated water/supplements & 3 & 7.89 \\
\hline FV in past 6 months & 14 & 36.84 \\
\hline Teeth brushed twice daily & 11 & 28.95 \\
\hline \multicolumn{3}{|l|}{ Risk factors } \\
\hline $\begin{array}{l}\text { M/PCG active decay past } 12 \\
\text { months }^{b}\end{array}$ & 26 & 68.42 \\
\hline M/PCG does not have dentist & 13 & 34.21 \\
\hline $\begin{array}{l}\text { Continual bottle/sippy cup with fluid } \\
\text { other than water }\end{array}$ & 20 & 52.63 \\
\hline Frequent snacking & 29 & 76.32 \\
\hline Special healthcare needs & 2 & 5.26 \\
\hline Medicaid eligible & 38 & 100 \\
\hline \multicolumn{3}{|l|}{ Clinical findings ${ }^{c}$} \\
\hline $\begin{array}{l}\text { White spots/visible decalcifications } \\
\text { past } 12 \text { months }^{b}\end{array}$ & 23 & 63.89 \\
\hline Obvious decay ${ }^{b}$ & 9 & 25 \\
\hline Restorations present ${ }^{b}$ & 15 & 41.67 \\
\hline Visible plaque accumulation & 20 & 55.56 \\
\hline Gingivitis (swollen/bleeding gums) & 1 & 2.78 \\
\hline Teeth present & 36 & 76.60 \\
\hline Healthy teeth & 10 & 27.78 \\
\hline \multicolumn{3}{|l|}{ Dental referrals ${ }^{d}$} \\
\hline Not made & 7 & 19.44 \\
\hline Made & 29 & 80.56 \\
\hline Completed & 21 & 72.41 \\
\hline
\end{tabular}

Note. The population size was $N=145$ and total sample size was $n=47$. All eligible dyads consented to participation in the project. The age range was $0.25-67$ months $(M=27.81, S D=20.62)$. Visit duration range 3.0-8.83 $\min (M=4.73, S D=1.28)$. WCC, well-child check; $n$, sample size; $M / P C G$, mother or primary caregiver. Two risk factors are based on the mother or primary caregiver's oral health.

${ }^{a}$ Eligibility was determined by at least 6 months of age or with first tooth eruption. Two participants were older than 6 months without first tooth eruption and one participant was 1 week old and had first tooth eruption.

${ }^{b}$ The child is designated high risk for caries if any of these risk factors or clinical findings are documented yes.

${ }^{c}$ Clinical findings were assessed in those with first tooth eruption $(n=36)$. ${ }^{d}$ Dental referrals were not based on high/low caries risk. Dental referrals were only made for those with first tooth eruption $(n=36)$ who had not seen the dentist in the past 3 months and without untreated decay. 
reduction strategies, brushing teeth twice daily with fluoridated toothpaste, cariogenic foods to avoid, and high risk behaviors. The educational guidance was tailored by the primary care provider based on responses and findings from the caries risk assessment. All caregiver/child dyads received age-appropriate oral health educational material that was reviewed in the clinic. Two handouts were sent home with the caregivers (Inter Tribal Council of Arizona 21 Tribal Nations Dental Prevention and Clinical Support Center, 2014; State of Wisconsin Department of Health Services, 2012). Finally, the primary care provider made a dental referral using a referral tracking slip for those children whose first tooth has erupted and who had not been seen by a dentist in longer than 3 months. In referral cases, the primary care provider instructed the caregiver to present their referral slip to the dental clinic staff immediately after their well-child visit for the well-dental visit and informed them that same-day appointments were readily available. The referral slips received by the dental clinic were counted at the end of each day to determine the success rate of the referral process from the pediatric clinic. This was the outcome measure of this project. Dental procedures performed by the dental team were not measured.

\section{Results}

Caregivers of children eligible for the caries risk assessment $(n=38)$ were assessed for their caries risk and protective factors (Boulter et al., 2011). Caregivers were asked if they had active decay in the past 12 months (yes; $n=26$, $68.42 \%$ ) and if they had a dentist (no; $n=13,34.21 \%$ ). The primary care provider recorded affirmative responses from caregivers for children's Medicaid eligibility $(n=38$, $100 \%)$, frequent snacking $(n=29,76.32 \%)$, continual bottle/sippy cup use with fluid other than water $(n=20$, $52.63 \%)$, medical special needs $(n=2,5.26 \%)$, established dental home $(n=19,52.78 \%)$, application of FV treatment in the past 6 months $(n=14,36.84 \%)$, twicea-day brushing $(n=11,28.95 \%)$, and use of fluoride supplements $(n=3,7.89 \%)$.

Clinical findings on those with tooth eruption $(n=$ 36) were as follows: white spots or visible decalcification $(n=23,63.89 \%)$, visible plaque accumulation $(n=20$, $50.56 \%$ ), restorations (i.e., fillings; $n=15,41.67 \%$ ), obvious decay $(n=9,25 \%)$, and gingivitis $(n=1,2.78 \%)$. Ten children $(27.78 \%)$ had healthy teeth. Participants were classified as high risk $(n=35,91.10 \%)$ and low risk $(n=$ 3, $7.89 \%$ ) for ECC.

Children with first tooth eruption $(n=36)$ who had positive clinical findings $(n=29,80.56 \%)$ and/or who had not seen a dental provider in the past 3 months were given same-day dental referrals. Seven children were not referred as they had seen a dental provider in the past 3 months and had no untreated dental decay. Twenty-one dental referrals were successfully completed $(72.41 \%)$.

The duration of each visit ranged from 3.0 to $8.83 \mathrm{~min}$ $(M=4.73 \mathrm{~min}, S D=1.28)$. All caregivers $(n=47,100 \%)$ indicated they would consent to having FV applied to their children at well-child visits if this service was offered at the pediatric clinic.

There was one unexpected result with an infant aged 1 week who had four primary teeth erupted. Because of young age, normally this participant would not be eligible for a caries risk assessment, but was assessed because of dentition. The caries risk assessment score for this case may have slightly skewed the results as these questions are not directed at newborns.

Additionally, there were two subjects who were older than 6 months and did not have first tooth eruption. A caries risk assessment was completed in these two cases, but not the clinical assessment of teeth. All caregivers were provided with age-appropriate education about ECC prevention as many parents did not know they needed to take care of the teeth even before they have erupted.

\section{Discussion}

The principal benefit to participation in this study was access to oral health education and early intervention through the dental referral process. Caregivers openly discussed age-appropriate oral health practices and had their questions answered. Risk factors and protective factors for ECC were discussed. The most important result of this project was that $74.1 \%$ of those referred were seen by the dental clinic.

Most children involved in this project were classified as high risk for ECC. Over half of the children were found to have visible plaque accumulation and one quarter had obvious decay. Restorations were found in more than one third of subjects and nearly two thirds had white spots or visible decalcification in the past 12 months. Caregiver's experience of active decay in the past 12 months was a prominent high risk factor for pediatric ECC in this sample population. Other common risk factors reported in over half of the subjects include continual bottle/sippy cup use with fluid other than water, frequent snacking, and being Medicaid-eligible.

Protective factors were less prevalent in this sample. Slightly over one quarter of children who had teeth brushed them twice daily, and just over one third have had FV applied in the past 6 months. All caregivers reported they would consent to FV application at well-child visits if it was offered at this venue. Nearly half of the children with first tooth eruption had never seen a dentist, and of those who had, the majority were treated for ECC. 
The outcomes of this project were congruent with those found in the literature. The caries risk assessment confirmed that this pediatric AI population was at high risk for ECC development (U.S. Department of Health and Human Services, 2000, as cited in Schroth et al., 2009). This intervention also proved to be easily implemented into a routine primary care visit as suggested by Pierce et al. (2002) and could potentially take less than 4 min when implemented in routine practice without the introductions, rapport building, and consent procedures required for this project.

More children visit a primary care provider than they do a dental provider (Hale et al., 2008), placing the primary care provider in an opportune position for oral health interventions described in this project. Evidence suggests that pediatric primary care providers should routinely assess pediatric oral health status at well-child visits and facilitate dental home establishment by the first year of life (Hale et al., 2003; Nowak \& Casamassimo, 2002). The results of this study confirmed that more children see the pediatrician than see the dentist.

Findings from this project add to the growing body of evidence that interprofessional education improves oral health. Braun et al. (2015) found that a similar oral health education program for nondental professions increased 16-fold the proportion of young, low-income children receiving oral health prevention services from a medical professional.

Future study should focus on the extent to which the integration of the oral health interventions can be deployed under routine circumstances to reduce ECC in this community (Riddle \& Clark, 2011). Sustaining the project based on the positive findings would involve the reallocation of staff time to integrate oral health screening, education, and referral into well-child visits.

The application of FV in the pediatric clinic is another area for future study. All caregivers reported they would consent to FV application if it were offered in the clinic. This finding aligns with the current evidence in that ECC development can be reduced with routine FV application at 6-month intervals at well-child checkups by a primary care provider (Arruda et al., 2012; Holve, 2006). Children ages 6 months to 5 years who are at high risk for ECC receive the most benefit (Lawrence et al., 2008).

Lewis et al. (2009) reported that most primary care providers reported routinely assessing patient's oral health status, but not applying FV even though research teams have consistently demonstrated significant reductions in dmfs scores with FV applications during well-child visits (Kranz et al., 2014; Slade et al., 2011; Weintraub et al., 2006). Reported reductions have varied from $18 \%$ to $25 \%$ in a 2 -year study (Lawrence et al., 2008). Holve (2006) reported reductions in dmfs of $35 \%$. Arruda et al. (2012) found that children ages 4-17 who received FV application at 6-month intervals had an overall $40 \%$ reduction in dmfs. Those who received two applications had a $49 \%$ reduction and those with only one application had a $31 \%$ reduction in dmfs. Thus, any FV application is helpful, but the greatest benefit occurs when applied at routine 6-month intervals. Marinho, Worthington, Walsh, and Clarkson (2013), in a review of three decades worth of FV studies, reported an average $43 \%$ reduction in dmfs and noted that FV confers substantial caries inhibiting effects in both permanent and primary teeth.

In addition to being an effective means of ECC prevention, routine FV application is also cost-effective. Quinonez, Stearns, Talekar, Rozier, and Downs (2006) found that FV applied at 9, 18, 24, and 36 months of age by primary care providers was more cost-effective than no varnish in providing an additional 1.52 cavity-free months per child between 9 and 42 months of age. Coupled with the understanding that $\mathrm{FV}$ is cost-effective and reduces ECC, the openness of parents and caregivers to having FV applied in the pediatric setting is an important finding of this project.

A strength of this project was the proximity of the dental and pediatric clinic. Providing medical and dental services in the same setting is one way to improve access to oral health care for AI families and underscores how the design of healthcare facilities can promote health. The integration of medical and dental services has been modeled by the Kalispell Indians at their Camas Washington Clinic (Kalispel Tribe of Indians, 2017), and the Northern Cheyenne Indians (Indian Health Service, 2017) at their Lame Deer Montana Clinic. The Coquille Indians of Oregon have included this model as a goal in their strategic plan for the future (Coquille Tribe, 2017).

A limitation to this project was the short duration. Though the sample size was ample, 2 weeks of data collection may not reflect typical attendance at the pediatric clinic. A second limitation was trying to accommodate same-day referrals near the close-of-business. In these cases, collaboration with the dental providers to facilitate hours of service later into the evening or next-day or same-week appointments should be considered. Additional measurements that would have strengthened this study include evaluating how caregivers comprehended the health education handouts and long-term follow-up with families to learn if they continued to visit the dentist regularly.

\section{Conclusions}

In conclusion, project results demonstrated that this pediatric oral health promotion and prevention project in a 
nondental, AI setting was both feasible and effective for delivering three evidence-based elements of ECC prevention. Project stakeholders were pleased to see that findings in this rural AI setting were like those reported by Braun et al. (2015), Pierce et al. (2002), and recommendations from the Academy of Pediatrics (American Academy of Pediatrics, 2011; American Academy of Pediatrics Division of State Government Affairs, 2013; Hale et al., 2008; Hale et al., 2003), demonstrating that interprofessional collaboration may be an essential and cost-effective element to solving the multifaceted problem of ECC (Indian Health Service Division of Oral Health, 2011). Oral health is important to overall health, and thus should be incorporated into routine well-child visits.

\section{Acknowledgments}

Contributions: KLM designed the project, completed the institutional review board application, and collected the data. LSL and KLM performed data analysis and interpretation, drafted the manuscript, and complied with the institutional review board requirements for approving the manuscript.

\section{References}

American Academy of Pediatric Dentistry. (2014). Policy on early childhood caries (ECC): Classification, consequences and preventive strategies. Oral Health Policies Reference Manual, 37(6), 50-52.

American Academy of Pediatric Dentistry. (2015). Policy on the dental home. Oral Health Policies Reference Manual, 37(6), 15-16.

American Academy of Pediatrics. (2008). Preventive oral health interventions for pediatricians. Pediatrics, 122, 1387-1394. https://doi.org/10.1542/peds. 2008-2577

American Academy of Pediatrics. (2011). Early childhood caries in indigenous communities. Pediatrics, 127(6), 1190-1198. https://doi.org/10.1542/peds. 2011-0847

American Academy of Pediatrics Division of State Government Affairs. (2013). More state Medicaid programs pay for children's oral health prevention services in doctors' offices. Retrieved from https://www2.aap.org/oralhealth/docs/ CelebratingOurWins.pdf

Arruda, A. O., Senthamarai Kannan, R., Inglehart, M. R., Rezende, C. T., \& Sohn, W. (2012). Effect of 5\% fluoride varnish application on caries among school children in rural Brazil: A randomized controlled trial. Community Dentistry and Oral Epidemiology, 40(3), 267-276. https://doi.org/10.1111/j. 1600-0528.2011.00656.X

Boulter, S., Crystal, Y., Duncan, P., Keels, M. A., \& Ramos-Gomez, F. (2011). American Academy of Pediatrics oral health risk assessment tool. Retrieved from https://brightfutures.aap.org/Bright $\% 20$ Futures \%20Documents/Oral\% 20Health\%20Risk\%20Assessment \%20Tool.pdf

Braun, P. A., Widmer Racich, K. W., Ling, S. B., Ellison, M. C., Reiner, L., Westfall, J. M., \& Savoie, K. (2015). Impact of an interprofessional oral health education program on health care professional and practice behaviors: A RE-AIM analysis. Pediatric Health, Medicine and Therapeutics, 101. https://doi.org/10.2147/phmt.s79826

Bridges, S. M., Parthasarathy, D. S., Wong, H. M., Yiu, C. K., Au, T. K., \& McGrath, C. P. (2014). The relationship between caregiver functional oral health literacy and child oral health status. Patient Education and Counseling, $94(3), 411-416$
Clark, M. B., Douglass, A. B., Maier, R., Deutchman, M., Douglass, J. M. Gonsalves, W., ... Bowser, J. (2010). Smiles for life: A national oral health curriculum. Retrieved from www.smilesforlifeoralhealth.com

Coquille Tribe. (2017). Strategic plan: Coquille Indian tribe. Retrieved from www. coquilletribe.org/docbin/strategicplanfinal121007.pdf

Du, Q., Yu, M., Li, Y., Du, H., Gao, W., Mei, H., \& Liu, S. (2017). Permanent caries experience is associated with primary caries experience: A 7-year longitudinal study in China. Community Dentistry and Oral Epidemiology, 45(1), 43-48. https://doi.org/10.1111/cdoe.12257

Duderstadt, K. G. (2014). Impact of Affordable Care Act on children's oral health: States hold the key. Journal of Pediatric Health Care, 28(6), 565-567. https://doi.org/10.1016/j.pedhc.2014.08.014

Dye, B. A., Thornton-Evans, G., Li, X., \& Iafolla, T. J. (2015). Dental caries and sealant prevalence in children and adolescents in the United States, 2011-2012. Hyattsville, MD: National Center for Health Statistics.

Hale, K. J., Keels, M. A., Thomas, H. F., Davis, M. J., Czerepak, C. S., \& Weiss, P. A. (2008). Preventive oral health intervention for pediatricians. Pediatrics, 122(6), 1387-1394. https://doi.org/10.1542/peds.2008-2577

Hale, K. J., Weiss, P. A., Czerepak, C. S., Keels, M. A., Thomas, H. F., Webb, M. D., \& Nathan, J. E. (2003). Oral health risk assessment timing and establishment of the dental home. Pediatrics, 111(5), 1113-1116. https://doi. org/10.1542/peds.111.5.1113

Holve, S. (2006). Fluoride varnish applied at well child care visits can reduce early childhood caries. Indian Health Service Primary Care Provider, 31(10), 243-246.

Indian Health Service. (2017). Northern Cheyenne service unit. Retrieved from https://www.ihs.gov/billings/healthcarefacilities/ncheyenne/

Indian Health Service Division of Oral Health. (2011). IHS early childhood caries collaborative. Retrieved from https://www.ihs.gov/doh/index.cfm? fuseaction=ecc.display

Inter Tribal Council of Arizona 21 Tribal Nations Dental Prevention and Clinical Support Center. (2014). Your baby's precious teeth are at risk for decay starting with the first tooth. Phoenix, AZ: American Dental Association. Retrieved from http://itcaonline.com/wp-content/uploads/2013/01/Brochure Your-Babysprecious-teeth-are-at-risk-for-decayl.pdf

Kagihara, L. E., Niederhauser, V. P., \& Stark, M. (2009). Assessment, management, and prevention of early childhood caries. Journal of the American Academy of Nurse Practitioners, 21(1), 1-10. https://doi.org/10.1111/ j.1745-7599.2008.00367.x

Kalispel Tribe of Indians. (2017). Camas center clinic. Retrieved from https:// kalispeltribe.com/camas-center-clinic

Kawashita, Y., Kitamura, M., \& Saito, T. (2011). Early childhood caries. International Journal of Dental Hygiene, 2011. https://doi.org/10.1155/2011/ 725320

Kranz, A. M., Rozier, R. G., Preisser, J. S., Stearns, S. C., Weinberger, M., \& Lee, J. Y. (2014). Comparing medical and dental providers of oral health services on early dental caries experience. American Journal of Public Health, 104(7), e92-e99. https://doi.org/10.2105/AJPH.2014.301972

Lawrence, H. P., Binguis, D., Douglas, J., McKeown, L., Switzer, B., Figueiredo, R., \& Laporte, A. (2008). A 2-year community-randomized controlled trial of fluoride varnish to prevent early childhood caries in Aboriginal children. Community Dentistry Oral Epidemiology, 36(6), 503-516. https://doi.org/ 10.1111/j.1600-0528.2008.00427.x

Lee, J. Y., Divaris, K., Baker, D. A., Rozier, R. G., Lee, S.-Y. D., \& Vann, W. F., Jr. (2011). Oral health literacy levels among a low-income WIC population. Journal of Public Health Dentistry, 71(2), 152-160. https://doi.org/10.1111/ j.1752-7325.2011.00244.x

Lewis, C. W., Boulter, S., Keels, M. A., Krol, D. M., Mouradian, W. E., O'Connor, K. G., \& Quinonez, R. B. (2009). Oral health and pediatricians: Results of a national survey. Academic Pediatrics, 9(6), 457-461. https://doi. org/10.1016/j.acap.2009.09.016

Marinho, V. C. C., Worthington, H. V., Walsh, T., \& Clarkson, J. E. (2013). Fluoride varnishes for preventing dental caries in children and adolescents. Cochrane Database Systematic Reviews, 11(7). https://doi.org/10.1002/ 14651858.CD002279.pub2 
Miller, E., Lee, J. Y., DeWalt, D. A., \& Vann, W. F., Jr. (2010). Impact of caregiver literacy on children's oral health outcomes. Pediatrics, 126(1), 107-114. https://doi.org/10.1542/peds.2009-2887

Nowak, A. J., \& Casamassimo, P. S. (2002). The dental home: A primary care oral health concept. Journal of the American Dental Association, 133(1), 93-98.

Nowak, A. J., Casamassimo, P. S., Scott, J., \& Moulton, R. (2014). Do early dental visits reduce treatment and treatment costs for children? Pediatric Dentistry, 36(7), 489-493.

Pender, N. J. (1982). Health promotion in nursing practice. New York: AppletonCentury-Crofts

Pierce, K. M., Rozier, R. G., \& Vann, W. F. (2002). Accuracy of pediatric primary care providers' screening and referral for early childhood caries. Pediatrics, 109(5), e82-e82. https://doi.org/10.1542/peds.109.5.e82

Plutzer, K., \& Keirse, M. J. (2011). Incidence and prevention of early childhood caries in one- and two-parent families. Child: Care, Health, and Development, 37(1), 5-10. https://doi.org/10.1111/j.1365-2214.2010.01114.x

Quiñonez, R. B., Stearns, S. C., Talekar, B. S., Rozier, R. G., \& Downs, S. M. (2006). Simulating cost-effectiveness of fluoride varnish during well-child visits for Medicaid-enrolled children. Archives of Pediatrics $\theta$ Adolescent Medicine, 160(2), 164-170. https://doi.org/10.1001/archpedi.160.2.164

Ramos-Gomez, F. J., Crystal, Y. O., Ng, M. W., Crall, J. J., \& Featherstone, J. D. (2010). Pediatric dental care: Prevention and management protocols based on caries risk assessment. Journal of the California Dental Association, 38(10), 746-761.

Ramos-Gomez, F. J., Crystal, Y. O., Ng, M. W., Tinanoff, N., \& Featherstone, J. D. (2010). Caries risk assessment, prevention, and management in pediatric dental care. General Dentistry, 58(6), 505-517; quiz 518-509.

Ricks, T. L., Phipps, K. R., \& Bruerd, B. (2015). The Indian Health Service early childhood caries collaborative: A five-year summary. Pediatric Dentistry, $37(3), 275-280$

Riddle, M., \& Clark, D. (2011). Behavioral and social intervention research at the National Institute of Dental and Craniofacial Research (NIDCR). Journal of Public Health Dentistry, 71, S123-S129.

Sams, L. D., Rozier, R. G., Wilder, R. S., \& Quinonez, R. B. (2013). Adoption and implementation of policies to support preventive dentistry initiatives for physicians: A national survey of Medicaid programs. American Journal of Public Health, 103(8), e83-e90. https://doi.org/10.2105/AJPH.2012.301138

Savage, M. F. (2004). Early preventive dental visits: Effects on subsequent utilization and costs. Pediatrics, 114(4), e418-e423. https://doi.org/10.1542/ peds.2003-0469-f
Schroth, R. J., Harrison, R. L., \& Moffatt, M. E. K. (2009). Oral health of indigenous children and the influence of early childhood caries on childhood health and well-being. Pediatric Clinics of North America, 56(6), 1481-1499. https://doi.org/10.1016/j.pcl.2009.09.010

Slade, G. D., Bailie, R. S., Roberts-Thomson, K., Leach, A. J., Raye, I., Endean, C., ... Morris, P. (2011). Effect of health promotion and fluoride varnish on dental caries among Australian Aboriginal children: Results from a community-randomized controlled trial. Community Dentistry Oral Epidemiology, 39(1), 29-43. https://doi.org/10.1111/j.1600-0528.2010. 00561.x

State of Wisconsin Department of Health Services. (2012). Healthy teeth for happy smiles P-44078. Retrieved from https://www.dhs.wisconsin.gov/library/ p-44078.htm

Twetman, S. (2016). Caries risk assessment in children: How accurate are we? European Archives of Paediatric Dentistry, 17(1), 27-32. https://doi.org/10.1007/ s40368-015-0195-7

Twetman, S., Fontana, M., \& Featherstone, J. D. (2013). Risk assessment-can we achieve consensus? Community Dentistry and Oral Epidemiology, 41(1), e64-e70. https://doi.org/10.1111/cdoe.12026

U.S. Public Health Service. (2000). Oral health in America: A report of the surgeon general. Retrieved from https://www.surgeongeneral.gov/library/ reports/

Vann, W. F., Jr., Lee, J. Y., Baker, D., \& Divaris, K. (2010). Oral health literacy among female caregivers: Impact on oral health outcomes in early childhood. Journal of Dental Research, 89(12), 1395-1400. https://doi.org/10.1177/ 0022034510379601

Warren, J. J., Weber-Gasparoni, K., Marshall, T. A., Drake, D. R., Dehkordi-Vakil, F., Dawson, D. V., \& Tharp, K. M. (2009). A longitudinal study of dental caries risk among very young low SES children. Community Dentistry and Oral Epidemiology, 37(2), 116-122. https://doi.org/10.1111/ j.1600-0528.2008.00447.x

Weintraub, J. A., Ramos-Gomez, F., Jue, B., Shain, S., Hoover, C. I., Featherstone, J. D. B., \& Gansky, S. A. (2006). Fluoride varnish efficacy in preventing early childhood caries. Journal of Dental Research, 85(2), 172-176. https://doi.org/10.1177/154405910608500211

Yu, A., Martin, K., Terpak, C., \& Curtis, M. (2009). Ambulatory surgery for early childhood caries in California 2005. Paper presented at the 15th Annual Maternal and Child Health Epidemiology Conference. Retrieved from https://www.cdph.ca.gov/programs/MCAHOralHealth/Documents/MOOHP-AmbulatorySurgery.pdf 